Bulletin d'Histoire Contemporaine de

I'Espagne

$54 \mid 2020$

Les espaces du politique dans l'Espagne du Trienio liberal (1820-1823)

\title{
Un empeño personal. Manuel Alonso de Viado y El Revisor político y literario (1820-1821)
}

Un engagement personnel. Manuel Alonso de Viado et El Revisor político y literario (1820-1821)

A personal commitment. Manuel Alonso de Viado and El Revisor político y literario (1820-1821)

Juan López Tabar

\section{OpenEdition}

\section{Journals}

\section{Edición electrónica}

URL: http://journals.openedition.org/bhce/2352

DOI: 10.4000/bhce.2352

ISSN: 1968-3723

Editor

Presses Universitaires de Provence

Edición impresa

Fecha de publicación: 1 enero 2020

ISSN: 0987-4135

\section{Referencia electrónica}

Juan López Tabar, « Un empeño personal. Manuel Alonso de Viado y El Revisor político y literario (1820-1821) », Bulletin d'Histoire Contemporaine de l'Espagne [En línea], 54 | 2020, Publicado el 01 julio 2020, consultado el 04 enero 2021. URL : http://journals.openedition.org/bhce/2352 ; DOI : https:// doi.org/10.4000/bhce.2352

Este documento fue generado automáticamente el 4 enero 2021.

Bulletin d'histoire contemporaine de l'Espagne 


\title{
Un empeño personal. Manuel
} Alonso de Viado y El Revisor político y literario (1820-1821)

\author{
Un engagement personnel. Manuel Alonso de Viado et El Revisor político y \\ literario (1820-1821) \\ A personal commitment. Manuel Alonso de Viado and El Revisor político y \\ literario (1820-1821)
}

Juan López Tabar

1 Cuando recibí la amable invitación de participar en el homenaje al añorado Alberto Gil Novales, pronto me vino a la cabeza la idea de centrar mi aportación en uno de tantos personajes secundarios que pulularon en aquellos apasionantes años en los que entró en crisis el Antiguo Régimen, y que ha permanecido desde entonces arrumbado a la espera de unas migajas de atención. Manuel Alonso de Viado es uno de ellos, y cumple además otro requisito caro a don Alberto, como responsable de un interesante periódico publicado durante el Trienio, que había recibido, como su autor, muy escasa atención hasta el momento. Decidí por lo tanto centrar mi escrito en Viado y su empresa periodística, que ahora traslado al lector en las páginas que siguen.

El interés prestado hasta el momento hacia nuestro protagonista había sido prácticamente nulo, a pesar de que, en vida, fue uno de los escasísimos españoles dignos de figurar en la Biographie des hommes vivants que publicara en París en 1816 el editor L. G. Michaud, y solo en fechas muy recientes ha merecido alguna atención ${ }^{1}$. Por ello, aunque el análisis de su papel durante el Trienio ocupará el espacio central del presente trabajo, su rica trayectoria personal merece que le dediquemos también cierta atención. Comenzaré por lo tanto por un esbozo de la carrera de este personaje hasta 1820. 


\section{La variopinta trayectoria de un joven ilustrado}

3 Manuel Alonso de Viado nació en Gijón el 27 de febrero de 1774. De familia hidalga, su padre, Joaquín Alonso de Viado Argüelles y Ordóñez, ejercía como procurador síndico general en la villa de Nava hasta que en 1773 se trasladó a Gijón «disfrutando de muchos bienes raíces que heredó de su padre» para ocupar el cargo de juez noble y contador mayor de rentas del Principado. En esta villa nació Manuel y poco después sus hermanos Joaquín (1779) y Francisco (1781)².

4 Nada sabemos de sus primeros años, ni del inicio de su formación académica. Algunas fuentes lo sitúan como estudiante de Derecho en la Universidad de Oviedo 3 , pero pronto debió de dar un giro a su carrera. Por el expediente de su sobrino, sabemos que en octubre de 1791 ingresó en la carrera militar, como cadete del Regimiento de infantería de León, alcanzando posteriormente los grados de subteniente y teniente. Entre tanto, estudió matemáticas en la Academia de Ingenieros de Zamora, y participó en la guerra de la Convención bajo las órdenes del príncipe de Castelfranco. Continuando con su ascenso en el escalafón, en agosto de 1795 era nombrado Ayudante Mayor «de los nobles de Asturias» con el grado de capitán. Al extinguirse este cuerpo pasó con el mismo grado al regimiento de Saboya (fugazmente) y luego al de Jaén, ya con el grado de mayor. En agosto de 1798 casó con María Josefa Zavala, natural de Guatemala ${ }^{4}$, motivo por el que ese mismo año solicita su agregación al regimiento de aquel destino. Su nombramiento, con el nuevo grado de sargento mayor, no se verificó hasta abril de 1800 , pero no llegará a ocuparlo debido a la guerra con Gran Bretaña ${ }^{5}$.

5 Su carrera en el ejército concluye en 1805. En febrero de aquel año lo encontramos ya dedicado a otros menesteres: pide licencia, desde Madrid, junto a Ambrosio Ortiz de Zárate, para abrir una fábrica de jabón en frío. Parece que quiere aplicar sus estudios de ingeniería al ámbito civil, e incluso, en su instancia, ambos emprendedores adjuntan planos de la máquina con la que pretende levantar su empresa. No pasó del papel: la autorización fue denegada ${ }^{6}$.

6 En el mismo año de 1805 detectamos ya sus primeras colaboraciones en la prensa madrileña que denotan su cercanía al círculo literario de Manuel José Quintana. Así, publica en el número XIX de las Variedades de Ciencias, Literatura y Artes una oda patriótica, fechada en 1798, «con ocasión de la infructuosa tentativa que hicieron los ingleses para bombardear Cádiz», y en el mismo año abanderará la defensa de la tragedia Pelayo, obra del propio Quintana vapuleada por los críticos, por medio de cinco cartas que ven la luz en el Diario de Madrid ( 31 de mayo, 1 y 26 de junio y 26 y 27 de julio). En estos escritos utilizaría el seudónimo de El Cobadongo que, como veremos, volverá a aparecer en el futuro ${ }^{7}$.

7 Todavía en 1805, publicará en el Memorial Literario una carta a los editores en la que, deplorando la carencia de una buena traducción castellana de Las vidas de los ilustres varones romanos y griegos de Plutarco, anuncia su disposición a afrontarla y presenta, a modo de avance, un fragmento del prólogo que abrirá su traducción y, unos días más tarde un «Fragmento de la vida de Flavio Máximo» ${ }^{8}$. Por desgracia estos son los únicos testimonios de esta ambiciosa empresa. No hemos encontrado otro rastro de esta supuesta traducción completa de la obra de Plutarco, ni en forma de artículos de prensa ni menos aún como libro impreso. 
8 Finalizado este año de 1805, en el que podemos suponer a Viado como residente en Madrid y atareado entre sus iniciativas industriales y su vena literaria, por fin en 1806 reanuda su vida laboral. En aquel año es nombrado Administrador general del Excusado y Real Noveno decimal del arzobispado de Granada. Allí se traslada y pronto da muestras de su inquietud cultural pues ya el 28 de julio de aquel año es elegido miembro de la Sociedad Económica de Granada «y más adelante segundo censor de la misma»' Unos meses más tarde Jovellanos celebraba en carta a Joaquín, hermano de Manuel, «la ventajosa situación del Sr. Don Manuel, hermano de Vd., y las esperanzas que abre a los ojos de su familia el buen concepto de sus jefes», en una misiva en la que aplaude también «su aplicación a la literatura, pues que la especie de trabajo que le dará su nuevo destino le hará mirar las musas agradables como un desahogo del fastidio inseparable de él $»^{10}$. La carta de Jovellanos no pasa de reflejar un pálido boceto de nuestro Manuel, pero se intuyen ya los trazos del prototipo de servidor ilustrado, con una carrera administrativa que se va consolidando, y que no renuncia a aspiraciones literarias de las que ya ha dado algún destello ${ }^{11}$.

9 En Granada le sorprendió la guerra y, ante la nueva coyuntura, es enviado «en calidad de diputado» a Sevilla para representar a la ciudad en la Junta de Sevilla ${ }^{12}$. Y, como muchos otros, cuando en 1810 los ejércitos franceses invaden Andalucía sin mayor oposición, «aceptó del ministro Azanza la administración de bienes llamados nacionales de Jaén, que desempeñó la mayor parte del año 10, y dejando un sustituto se vino a Madrid pero conservando en propiedad aquel destino» ${ }^{13}$.

\section{Navegando por aguas turbulentas: de la guerra al exilio; entre la fe masónica y el juicio inquisitorial}

10 Suponemos por lo tanto a Viado en la Corte hacia finales de 1810. No tenemos constancia de que, en la capital, desempeñara cargo alguno, pero sí de su paso por foros de sociabilidad, como la Sociedad Económica Matritense, en la que ingresó en marzo de $1811^{14}$, y, muy destacadamente, en la Logia de Santa Julia, uno de los talleres masónicos de la capital donde, como vamos a ver, se mostró como uno de su más activos (y valientes) miembros. En efecto, no fue el único josefino que se vio atraído por el ideal masónico, pero sí uno de los pocos que, entonces, tuvo los arrestos para mostrar en público su filiación masónica. Así, en la Colección de piezas de arquitectura trabajadas en el taller de Santa Julia, una recopilación de escritos, poemas y discursos publicada sin indicación de lugar ni año (pero a todas luces ya en 1812 o 1813, cuando el declive del régimen josefino era patente), los únicos trabajos firmados son precisamente los de Manuel Alonso de Viado. En uno de ellos, respondiendo a la pregunta ¿Cuál será la influencia de la masonería en la felicidad de la España?, se muestra esperanzado en su sano influjo en el país de la Inquisición y los Jesuitas y concluye exaltado: «jOh masonería! (...) A ti sola es encargado el augusto ministerio de extirpar las semillas de una fanática insurrección; a ti dado únicamente entronizar la virtud, derrocar el vicio (...) Sustituirás la luz a las tinieblas, la libertad de conciencia a la esclavitud de la razón, la dulzura de costumbres al carácter sombrío y fiero, la doctrina de los filósofos del siglo XVIII al detestable fárrago de los casuistas» ${ }^{15}$.

11 Los escritos de Viado durante la guerra, que ya en 1813 saltarán también a las páginas, menos recónditas, de la Gaceta de Madrid, nos muestran a un personaje que ha abrazado con verdadera convicción la causa josefina, que ve en el nuevo régimen la 
oportunidad de una anhelada regeneración de España y se implica personalmente en su cruzada contra la intolerancia religiosa, principal causa de la decadencia española, a la vez que rechaza la condescendencia supremacista de algunos escritores europeos que ven en unos presuntos defectos originarios, casi genéticos, de los españoles, la causa de nuestra incapacidad para el progreso ${ }^{16}$.

El patriota de 1808 terminaba la guerra como un hombre sinceramente comprometido con unos ideales que supo defender con una valentía fuera de lo común, en una postura que le llevaría poco después camino del exilio ${ }^{17}$. Como buena parte de sus compañeros de infortunio, vivirá unos meses de auténtico trasiego entre unos depósitos de refugiados y otros. Así, en septiembre de 1813 las fuentes lo sitúan en Toulouse, donde se exilia inicialmente con mujer y cuatro hijos. Allí, el prefecto de Haute-Garonne le nombrará miembro de la comisión de distribución de socorros entre sus compañeros. Unos meses más tarde, en abril de 1814, figura entre los firmantes en Montpellier de una exposición al monarca francés junto con más de 250 compañeros, y solo unas semanas después, en mayo de 1814, estaba de nuevo en Toulouse, donde lo encontramos ya encabezando de nuevo, junto con otros dos refugiados españoles, una comisión española que se dirige por carta a Talleyrand en solicitud de nuevas ayudas ${ }^{18}$.

Pero con el asentamiento de Luis XVIII en el trono parece que la suerte de Viado mejora (al contrario de la de la mayoría de sus compañeros refugiados, que continuarán con una vida itinerante y precaria entre un depósito y otro). En octubre de 1814 Viado, que todavía reside en Toulouse «obtiene la autorización de establecer su domicilio en Francia, y el disfrute de todos los derechos civiles, mientras siga residiendo en el país» ${ }^{19}$, y el mismo mes, si hemos de creer el testimonio de su sobrino, era condecorado con la flor de Lis $^{20}$.

14 Su situación legal se va estabilizando, y, entre tanto, no permanece ocioso. En febrero de 1815 era nombrado académico correspondiente de la Académie des Sciences, Inscriptions et Belles-Lettres de Toulouse ${ }^{21}$, y en abril de 1816 hacía lo propio en la Société des Antiquaires de France ${ }^{22}$. Para entonces residía ya en París, al menos desde septiembre de $1815^{23}$.

15 La buena estrella de Viado no parece fruto de la casualidad. Sin duda se trata de un hombre bien formado, que ha dado destellos de la calidad de su pluma desde sus primeros escritos a principios de siglo, y de lo avanzado de algunas de sus ideas políticas y filosóficas, según hemos visto en sus escritos de 1812 y 1813. Pero más allá de su brillantez personal, sin duda tuvo que tener amigos poderosos (que por el momento no hemos identificado), pues solo los refugiados de relevante estatus social (y no era el caso de nuestro hombre) podían alcanzar en tan breve espacio de tiempo tales privilegios (muy especialmente el permiso de residencia en París, negado a tantos otros). Un nuevo indicio da fe de su buen posicionamiento: en 1816 será uno de los escasísimos españoles, como vimos, que tendrán el honor de formar parte de la Biographie des hommes vivants de L. G. Michaud, donde es descrito como un «acendrado partidario de las monarquías constitucionales» ${ }^{24}$.

16 Su acomodo en París, con una aureola de hombre de letras, no será definitivo. En una nueva vuelta de tuerca, lo encontramos en 1818 asentado en Burdeos, y esta vez con una nueva ocupación que ya no abandonará en el resto de su vida: los negocios. En efecto, desde mediados de aquel año se encuentra asociado a la casa de comercio de Marc Gémusés, y, en calidad de comerciante, regresa a España a finales de noviembre de aquel año. Su intención era permanecer dos o tres meses en Madrid para gestionar 
unos negocios de la mano de su socio bordelés, pero el 22 de febrero de 1819 es detenido a petición de la Inquisición.

El expediente inquisitorial no aclara del todo la naturaleza de estas gestiones, pero por otros indicios parece que podrían estar relacionadas con las oportunidades que se iban abriendo en los territorios americanos ${ }^{25}$. Ya en enero de 1819 su presencia es detectada en la capital e, inmediatamente, el Inquisidor general, que está al tanto de sus escritos en la citada Colección de piezas de arquitectura, solicita su detención. En el auto, Viado es descrito como «el más instruido en los misterios [de la masonería], el más hábil y el de mejor pluma, y también el más decidido y furioso, como que ha bebido sus doctrinas en Voltaire y el frenético Diderot», y, en definitiva, «un hombre irreligioso dedicado a fomentar la revolución» ${ }^{26}$.

Las acusaciones son graves, y Viado intenta sortearlas desmintiendo la autoría de sus escritos, con argumentos que «tienen todas las señales de un arbitrio imaginario» en palabras del calificador de la Inquisición. Pero pronto intercederán por él desde Francia, en un nuevo indicio del posicionamiento social que ha logrado en los últimos años. Así, el 30 de marzo de 1819 el conde de Hauterive, antiguo ministro de Asuntos Exteriores y bien relacionado con el gabinete del duque de Richelieu, escribe al embajador español en París, conde de Fernán Núñez, interesándose por el prisionero, al que califica como negociante «rebosante de honor y probidad» («plein d'honneur et de probité») enteramente ajeno a cualquier otra mira que la de sus negocios y achacando su detención a posibles envidias y calumnias ${ }^{27}$. Finalmente, tras pasar más de dos meses en la cárcel, se decreta su expulsión inmediata de España. En junio de 1819 estaba ya de vuelta en su país de acogida.

\section{«El momento más favorable para hablar»: la empresa periodística de Viado}

Es este el hombre, el joven ilustrado de esmerada formación, el militar que entrega el sable tras años intensos en la milicia ${ }^{28}$; el escritor que afina su pluma en las principales cabeceras de la época, el patriota y pronto convencido josefino, el masón que defiende sus ideales con valentía poco común, el padre de familia que vive la experiencia del exilio, y también el hombre de negocios que va abriéndose camino, es el hombre -decíaque pocos meses después de su paso por las cárceles inquisitoriales regresa a su patria en los primeros compases del nuevo régimen constitucional.

No tenemos constancia exacta de su llegada al Madrid efervescente de 1820, pero tuvo que ser al poco tiempo de triunfar el golpe de Riego. Un periódico, y más cuando es un empeño personal, solitario, no se improvisa fácilmente, por lo que suponemos a Viado asentado en la capital ya en los primeros compases del régimen, presumiblemente dedicado a los negocios y pronto volcado en una empresa desde la que se lanzará a la palestra pública: su periódico.

21 El Revisor político y literario, que así se llamó, salió a la calle el 10 de agosto de aquel año. No había sido este el título elegido en primera instancia: como explica su autor en la «Advertencia» que abre el primer número, anunció y distribuyó el prospecto de su periódico bajo el título de El Censor, pero justo entonces «apareció otro que tomó la misma denominación». Confiaba, dice, «que le distinguirían del nuestro llamándole Censor semanal, mas como saliesen frustradas nuestras esperanzas, hemos 
determinado mudar el nombre de nuestro periódico» ${ }^{29}$. Se trató de una aventura decenal, que salía los días 10, 20 y 30 de cada mes, en números de 24 páginas que, inicialmente, se vendían en cuatro librerías madrileñas, con la posibilidad de suscripción en cualquier administración de correos del reino. Paulatinamente la distribución fue mejorando, llegando sus ejemplares a al menos otras 17 ciudades, pero la empresa se agotó a los pocos meses: el 30 de enero de 1821 aparecía la última entrega tras haber publicado dos tomos, cada uno de ellos con nueve números («cuadernos» los llama su autor) ${ }^{30}$.

La estructura del periódico no era fija, y los temas, como veremos a continuación, variados. La convulsa y apasionante política nacional es omnipresente en sus páginas, como no podía ser menos, pero habrá hueco también para los temas americanos, la economía o artículos con mayor peso doctrinal o filosófico, sin descuidar los breves apuntes de política europea (extractos en la mayoría de ocasiones de otros periódicos,

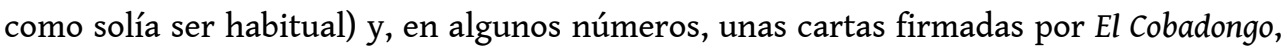
pseudónimo que rescata Viado de tiempos pasados, como hemos visto anteriormente.

Se trata de una empresa personal, sostenida por el bolsillo y la pluma de un único personaje: el propio Viado. Habiendo sido Manuel un convencido afrancesado, no faltarán los testimonios que hermanan al Revisor con cabeceras dirigidas por exjosefinos. Así, la Periodicomanía, en un artículo destinado a agrupar a los periódicos madrileños según «la calle» en la que residen, empareja al periódico de Viado con $E l$ Censor, ambos sin domicilio fijo "y en un pie como las grullas»" ${ }^{31}$ y El Constitucional, en una clasificación de la prensa madrileña, incluía en el grupo de los «antiministeriales» a «la Miscelánea, El Censor, El Revisor» y el propio Constitucional ${ }^{32}$. Y por supuesto, su salida a la calle en agosto de 1820 fue saludada con buenas palabras por colegas como Javier de Burgos, que desde la Miscelánea ponderaba su «juicio y buen estilo», o los editores de El Universal (todos ellos josefinos) que aprobaban su «acertada elección de materias, una crítica sagaz y juiciosa» $y$, ante todo, «su moderación $»^{33}$.

24 Más allá de estas menciones, El Revisor comparte desde luego con sus colegas afrancesados algunos rasgos $^{34}$. Así, desde los primeros números hace una apelación al gradualismo en las medidas, cuando avisa al lector de que «no todo se ha de decir al golpe y de un trompón. Cada cosa requiere de su tiempo (...). La naturaleza no hace milagros, y cuatro capítulos de Rousseau y de Mably no son bastantes a educarnos de nuevo y a desarraigar de nuestros corazones el espíritu de intolerancia que nos han transmitido nuestros abuelos», en una llamada a la paciencia ante las resistencias a los cambios, que coincide casi a la letra con la que, por las mismas fechas, firmaba Manuel Silvela desde Burdeos ${ }^{35}$. Un gradualismo que no debe confundirse con la inacción o la pérdida de tiempo, que denunciará ya en el número 4, cuando, en un artículo destinado a analizar el trabajo del gabinete, critica «la tibieza y lentitud en acelerar las suspiradas reformas» $\mathrm{y}$ avisa del peligro del desencanto popular con el nuevo régimen: «¿Imaginan que se ha adelantado algo, mientras el labrador, el artesano y el comerciante no conozcan por efectos sensibles y materiales las ventajas del nuevo sistema?» ${ }^{36}$.

Este marcaje férreo a la labor de las Cortes y del Gobierno, en el que coincide con sus correligionarios, llevará ya en el mes de octubre a rozar el desencanto, en una ácida descripción que, aunque algo larga, merece la pena insertar:

«He aquí lo que constituye un ministerial perfecto. Invocar eternamente la Constitución, cuando se interpreta en favor suyo; olvidarla o desatenderla si cualquiera de sus artículos se opone a sus proyectos ambiciosos; alegar en apoyo de sus 
providencias las circunstancias del tiempo en que vivimos o el triste estado de la opinión pública (...); reunirse todas las noches para concertar planes que mantengan en el Congreso nacional la mayoría que sofoca los clamores de los independientes, o para penetrarse del sentido en que se ha de hablar al día inmediato, ora amenazando a los unos, ora lisonjeando a los otros; pensar continuamente en colocar a sus deudos y paniaguados, sin consultar sus disposiciones, y anteponiéndolos siempre a hombres beneméritos $(. ..) »^{37}$.

Comparte también con sus colegas exjosefinos cierto elitismo, que lleva a Viado a alabar la ley electoral francesa «porque deposita en manos de la clase media de la sociedad el derecho de nombrar diputados para desconcertar las intrigas de la aristocracia y huir de la tumultuosa efervescencia del pueblo», un modelo (que bebe sin duda del doctrinarismo francés) que pretende trasladar a España, cuando aspira a que el congreso esté formado fundamentalmente por «hacendados, dejando lugar para que el hábil comerciante, el magistrado distinguido por sus luces y el hombre estudioso y sabio, puedan cooperar a la formación de las leyes, sin el peligro de llenar las Cortes de diputados sin haberes y quizá sin más mérito que el de una dañosa popularidad» ${ }^{38}$.

Pero no todo serán coincidencias. El periódico de Viado comparte, como vamos viendo, algunas de las características de las más conocidas cabeceras redactadas por antiguos afrancesados, pero el Redactor, como empresa particular, trasluce algunas ideas propias que en ocasiones lo distancian de las páginas de la Miscelánea o El Censor. Una de las más relevantes es, sin duda, el papel que Viado atribuye a los ciudadanos: el control del gobierno mediante el arma de la opinión pública. Y aquí podemos observar algunas diferencias. Coincide nuestro hombre con los Lista, Burgos o Hermosilla al señalar la relevancia de la libertad de imprenta, cuya defensa entablará en vanguardia El Censor desde su primer número ${ }^{39}$. Así, al igual que sus compañeros de infortunio, también Viado proclamará que «si nos pusieran a escoger entre todos los derechos (...) escogeríamos la libertad de escribir, porque teniéndola es indispensable recobrar muy en breve todos cuantos nos hubiesen usurpado» ${ }^{40}$. Pero... no es ésta la única arma con la que cuenta la ciudadanía: «el órgano natural de la opinión pública en los países libres son sin disputa las juntas populares y la libertad de imprenta» ${ }^{41}$. $Y$ aquí chocará Viado de frente con sus antiguos compañeros. En efecto, mientras El Censor, desde su número inicial, abominaba de las sociedades patrióticas, deslegitimándolas como medio de expresión de la voluntad popular, desde El Revisor, aludiendo (sin citarlo) al semanario de Lista, Miñano y Hermosilla, se defiende su legalidad; su utilidad «porque en ellas se descubre el estado de la opinión popular»; su conveniencia "porque difunden y conservan el amor de la patria», y su necesidad, porque "con el celo y la vigilancia de sus miembros se desconciertan las conspiraciones» ${ }^{42}$. Una defensa que aún mantendría unos meses más tarde cuando, crítico con las restricciones que el gobierno pretende aplicar a estas reuniones, avisa que «quitadas las sociedades populares, en vez de señalarles límites que nunca debieran traspasar, podrán los ministros amañar en las elecciones» ${ }^{43}$.

Y si comparte con sus antiguos compañeros ciertas restricciones elitistas en el acceso a los cargos públicos, no se percibe en El Revisor, al menos de forma tan acusada, el temor al pueblo que se detecta en las páginas de El Censor o la Miscelánea. Desde sus páginas, Viado defenderá que «donde quiera que se manifieste la opinión pública, allí existe un elemento democrático, que en vez de peligroso, es sumamente útil, es indispensable en los gobiernos representativos». Tampoco faltarán las denuncias ante la falta real de 
igualdad que, por su tono, hubieran firmado cabeceras más radicales como El Zurriago ${ }^{44}$, o apasionadas defensas de la tolerancia ${ }^{45}$.

¿Cabe por ello calificar al Revisor de "prensa afrancesada» durante el Trienio? Sí, si consideramos la filiación de su autor durante la guerra, pues hubo pocos josefinos más decididos que Viado, como hemos bosquejado; y como sus compañeros de infortunio conoció el exilio. Pero aunque comparte, como hemos visto, algunas orientaciones doctrinales con las cabeceras prototípicas de la prensa afrancesada de aquel momento, Viado imprime a su periódico un sesgo puramente personal. Contempla la implantación del nuevo régimen como un momento histórico («hay un intervalo de dos siglos y medio entre el año de 1819 y el de $1820 »$, dirá ${ }^{46}$ ) y, en estas circunstancias, como ciudadano comprometido se decide a actuar desde su deseo sincero del sostenimiento del régimen. Por algo eligió como sello de su periódico un verso de la Eneida de Virgilio: Mollissima fandi tempora, es decir: «el momento más favorable para hablar». Y Viado no quiere quedarse callado: por ello criticará al gobierno, y duramente, cuando deba hacerlo, pero no dejará de clamar por la unión entre los liberales ${ }^{47}$, ni de proponer reformas de todo tipo ${ }^{48}$.

El periódico sobrevivió apenas seis meses. Ya a finales de diciembre de 1820 se citaba a Viado como próximo redactor de El Constitucional, uno de los periódicos con los que mejores relaciones había mantenido su cabecera. El rumor sería desmentido por los propietarios de este periódico, y el propio Viado lo aclaró en un «Aviso» en el que confirmaba que no cambiaría de cabecera y anunciaba que, aunque El Revisor terminaría con la novena entrega del segundo tomo, «tenemos intención de sacar a luz con el mismo título a épocas indeterminadas algunos cuadernos» promesa que, que sepamos, no llegó a cumplir ${ }^{49}$. La aventura terminó definitivamente con el último cuaderno, aparecido el 30 de enero de 1821. Esta salida en falso motivó un gracioso comentario de la Periodicomanía, que, cuando parecía que iba a cerrar, pero no lo hizo, le dedicó un «Medio epitafio en prosa» que transcribo a continuación:

«Revisor hermano nu...

que estás por un lado muer...

y te embocas en el cuer....

de ese nuevo constitu...

Medio toquen las campa...

recibe este medio epi...

los que asistan al enti...

digan: requiescat in pa....1 ${ }^{50}$

Así terminaba la aventura periodística de Manuel Alonso de Viado. Y con ella, también su protagonismo en estos años, pues a partir de ahora su rastro se difumina casi por completo. Según anunció en el «Aviso» que hemos mencionado, pensaba dedicarse a «perfeccionar la traducción de la Historia de América del doctor Robertson que tiene concluida años hace», obra para la que incluso llegó a abrir una suscripción que anunció en el último de los cuadernos de El Revisor ${ }^{51}$. Por desgracia no hemos podido encontrar rastro de esta supuesta traducción, que, según se dice en la Biographie des hommes vivants, presentó en su momento a Azanza, a la sazón ministro de Indias josefino, «avec des notes, critiques, historiques et politiques» ${ }^{52}$.

No tenemos constancia de nuevas colaboraciones en la prensa del Trienio, y de hecho su nombre ya no figurará entre el elenco de periodistas que recoge Manuel Eduardo de 
Gorostiza en su Galería en miniatura de los más célebres periodistas, folletistas y articulistas de Madrid (Madrid, Impr. de Eusebio Álvarez, 1822) ni tampoco en el Apéndice a la Galería que la completó. Con todo parece que siguió interesado en el devenir del régimen constitucional, incluso más allá de julio de 1822, cuando el ascenso al poder de los gabinetes exaltados acabó por espantar a la mayor parte de sus congéneres afrancesados. Apenas es un indicio, pero en noviembre de aquel año presentó a las Cortes una Memoria sobre el modo de fiar la suerte del clero, texto que los señores diputados acogieron con agrado y que pasó, para su estudio, a la comisión eclesiástica ${ }^{53}$.

Poco puedo aportar sobre su devenir en los siguientes años. Por algunos indicios que he podido espigar aquí y allá, no parece que se viera forzado a exiliarse y, por el contrario, debió de proseguir con éxito su carrera como comerciante y hombre de negocios, afianzándose así en una trayectoria que había comenzado unos años antes, como hemos visto ${ }^{54}$. En 1829 el Ayuntamiento y Consulado de Cádiz nombraba a Viado, «del comercio de dicha capital», apoderado general en Madrid «en los negocios relativos al puerto franco" ${ }^{55}$, y pocos años después, con el cambio de régimen, sería reclamado por diferentes gobiernos para ejercer varias comisiones. Así, en enero de 1834, el entonces ministro Javier de Burgos le encarga el estudio «del subsidio del comercio» que «pesa de una manera embarazosa sobre el tráfico y circulación interior $»^{56}$, y un año más tarde se requerían de nuevo sus servicios como parte de una comisión encargada de «simplificar y mejorar el sistema de contribuciones» ${ }^{57}$.

Parece por lo tanto que en estos años se dedicó, suponemos que con éxito, a los negocios ${ }^{58}$. Y aún tendrá tiempo para dar muestras de su interés por la Economía en trabajos como una Memoria leída en la sección de ciencias políticas y morales del Ateneo de Madrid sobre si conviene o no abolir los diezmos en España ${ }^{59}$, y un año más tarde publicaba en la Revista de Madrid un largo artículo titulado «De los empréstitos y de la deuda pública de España» ${ }^{60}$.

El joven ilustrado, prototipo de los jóvenes de 1808, bien formados y con experiencia en la administración, devenido ferviente masón durante la guerra y periodista comprometido con el régimen liberal durante el Trienio, acabó siendo en su madurez un hombre de negocios, cuya experiencia es requerida desde diferentes ámbitos. El viejo Viado es ya un hombre mucho más moderado (trayectoria nada ajena, por otra parte, a muchos de sus compañeros de generación) y unos años más tarde culminaría su periplo con un breve paso por la alcaldía de Madrid en $1844^{61}$. En mayo de aquel año se hizo cargo de organizar las elecciones municipales en la capital y en los informes que diariamente enviaba a la reina María Cristina celebra el «completo triunfo de la razón y de la justicia» que identifica por supuesto con el partido moderado, éxito en el que, dice, «he tenido una parte muy principal». Incluso le anuncia que, ante las inminentes elecciones a Cortes, «mis amigos exigen de mí que me presente como candidato y emplee todos mis recursos y popularidad para sacar triunfante al partido moderado» ${ }^{62}$.

Desconozco si llegó a concurrir a unas elecciones, pero no tenemos constancia de que nuestro hombre lograra finalmente un acta como parlamentario. Nuestras últimas noticias datan precisamente de aquel verano de 1844 cuando, en el viaje hacia los baños de Bagnères de Bigorre visitó la casa de Miñano en las cercanías de Bayona. Es al menos lo que se deduce de una carta del viejo Miñano a Luis Alonso de Viado, hijo de Manuel, en la que se refiere a él como «nuestro querido enfermo», pero no tengo dato alguno sobre su fallecimiento. Con todo, este testimonio da fe de una amistad, o al menos una 
cercanía, cuyo origen desconozco pero que pudo muy bien ser antigua, con uno de aquellos viejos josefinos que han protagonizado no pocos de mis anteriores escritos ${ }^{63}$.

\section{NOTAS}

1. El mérito corresponde a Juan Pablo Domínguez, quien recientemente ha publicado «Fanatismo religioso y decadencia nacional. Los escritos afrancesados de Manuel Alonso de Viado», Mélanges de la Casa de Velázquez, oㅜ 47-2, 2017, p. 207-228. Agradezco a Juan Pablo Domínguez las valiosas informaciones que me ha transmitido.

2. Los datos proceden del expediente de nobleza de Joaquín $M^{a}$ Eduardo Alonso de Viado y Ribes, sobrino de Manuel, fechado en 1829 (AHN, Universidades, leg. 672, exp. 37). En otras biografías se indica como año de nacimiento 1775 , pero el citado expediente incluye la partida de bautismo de nuestro personaje.

3. Biographie étrangère, ou galerie universelle, historique, civile, militaire, politique et littéraire..., Paris, Alexis Eymery, 1819, p. 17.

4. Era hija de Agustín de Zavala, natural de Lequeitio, que marchó a hacer fortuna a Guatemala, donde casó en 1776 y donde nace su hija. En fecha indeterminada la familia Zavala regresa a la península, instalándose en el Puerto de Santa María, donde María Josefa contrajo matrimonio con Manuel. Tomo estos datos de Joaquín Zavala Urtecho, «Huellas de una familia vascocentroamericana en cinco siglos de historia», Revista Conservadora del Pensamiento Centroamericano, XXIII/3, 1970, p. 292.

5. El cursus honorum procede del citado expediente de su sobrino (p. 15 y ss.) En cuanto a su solicitud de 1798 puede verse online y procede del Archivo General de Indias, SGU, leg. 6937/12. El nombramiento definitivo en Gaceta de Madrid, 22 de abril de 1800, p. 323.

Julio Somoza, en un viejo trabajo (Jovellanos: nuevos datos para su biografía, Madrid, Fernando Fé, 1885 , p. 224), lo menciona como alumno del Real Instituto Asturiano de Náutica y Mineralogía, fundado por Jovellanos en 1794. ¿Fue un paso fugaz, compatible con su carrera militar? No hay manera de saberlo, pero la vinculación del político asturiano con la familia Viado existió, como luego veremos.

6. El expediente en AHN, Hacienda, leg. 319, exp. 19.

7. Tomo estas noticias de Leticia Villamediana González, «La anglomanía en la prensa periódica española durante la segunda mitad del siglo XVIII», en VV.AA., Hacia 1812 desde el siglo ilustrado, Madrid, Sociedad Española de Estudios del siglo XVIII - Gijón, Trea, 2013, p. 207-208.

8. En el avance de su prólogo (publicado en el n⿳o XXXIV de 10 de diciembre de 1805, p. 289-299), pondera la importancia de Plutarco, y tras glosar la única traducción castellana disponible, la de Alonso de Palencia de 1491, habla de otras ediciones europeas de los siglos XVI a XVIII que ha tenido a la vista. El citado fragmento de la «Vida de Flavio Máximo» ocupa las p. 335-374 del no XXXV (20 de diciembre), en el mismo tomo. Al final del mismo, los editores del Memorial Literario celebran la iniciativa de Viado del que alaban «su exactitud, su anhelo indagador y su conocimiento en las lenguas que traduce y en que escribe», y avanzan que «con la mayor sinceridad ha sujetado sus ensayos al dictamen de algunos inteligentes, que con sus imparciales consejos le han animado a que concluya su plan tan felizmente como ha principiado» (p. 377-378).

9. De nuevo recurro al citado expediente del sobrino de Viado. 
10. Jovellanos a Joaquín Alonso de Viado, Bellver, 21 de febrero de 1807, en Gaspar Melchor de Jovellanos (José Miguel Caso González, ed.), Obras Completas, t. IV, Oviedo, Instituto Feijoo de Estudios del siglo XVIII, 1988, p. 411. Juan Llabrés en «Diario de don Gaspar Melchor de Jovellanos en el castillo de Bellver», Bolletí de la Societat Arqueològica Luliana, nº 598, 1930, p. 187, identificó a Viado como «el amiguito» que se cita en sus páginas, pero no he podido certificarlo.

11. Antonio Calvo Maturana ha estudiado muy bien esta figura del cargo medio administrativo ilustrado en el reinado de Carlos IV. Remito a su interesante trabajo Cuando manden los que obedecen. La clase política e intelectual de la España preliberal (1780-1808), Madrid, Marcial Pons, 2013.

12. Así se asegura en la información que facilita la Biographie des hommes vivants, p. 53. No he localizado testimonios de su actividad en esta Junta.

13. Utilizo ahora su expediente conservado entre los papeles de Fernando VII del Archivo General de Palacio, t. XIX, carpeta 14. En efecto, en 1813 aún seguía figurando como Administrador de Bienes Nacionales de la prefectura de Jaén en las listas de refugiados afrancesados que se elaboraron conforme cruzaban la frontera. Con todo, su paso por el cargo parece fugaz, y apenas es citado en la monografía que redactaron Manuel López Pérez e Isidoro Lara Martín-Portugués, Entre la guerra y la paz. Jaén (1808-1814), Universidad de Granada-Ayuntamiento de Jaén, 1993.

14. Concretamente el día 30. En enero de 1813 sería nombrado Censor. Agradezco a Elisa MartínValdepeñas, gran conocedora de la historia de esta institución, estas informaciones.

15. Colección de piezas de arquitectura..., op. cit., p. 127-136 (la cita en p. 134). Viado reaprovechará el texto de este discurso en el futuro, publicándolo casi literalmente (con la sola omisión de algún párrafo y el uso estratégico de algunos sinónimos) en El Revisor, como veremos.

16. Remito, en todo lo referente a este asunto, al citado trabajo de Juan Pablo Domínguez, «Fanatismo religioso y decadencia nacional...». Domínguez, que analiza con detenimiento estos escritos, considera en otro trabajo («Tolerancia religiosa en la España afrancesada (1808-1813)», Historia y política, $\mathrm{n}^{\circ} 31,2014$, p. 220) que Viado llegará a defender la necesidad de cambiar la Constitución de Bayona para instaurar una auténtica libertad religiosa, una postura que le acerca a lo que, solo unos pocos años después, plantearán los autores de la nonnata constitución de 1819, estudiada magistralmente por Claude Morange, Una conspiración fallida y una constitución nonnata (1819), Madrid, CEPC, 2006.

17. Su osadía, que como veremos, le pasará factura unos años más tarde, tan solo es comparable a la de otro personaje de personalidad extraordinaria, como el abate Marchena, quien en 1812 se despachaba con un durísimo artículo contra el gobierno patriota: «Al gobierno de Cádiz», Gaceta de Madrid, 27-29 de julio de 1812 (véase mi artículo «La mirada crítica. Los afrancesados ante la revolución española», en Fernando Durán López y Diego Caro Cancela (eds.), Experiencia y memoria de la revolución española (1808-1814), Cádiz, Universidad de Cádiz, 2011, p. 99-119).

18. El primer indicio procede de las listas de refugiados que coordinó Miguel José de Azanza en septiembre de 1813 (sobre su gestación y procedencia, remito a mi libro Los famosos traidores. Los afrancesados durante la crisis del Antiguo Régimen (1808-1833), Madrid, Biblioteca Nueva, 2001, p. 19-22); su presencia en Montpellier procede de AHN, Estado, leg. 5.244; en cuanto al rastro en Toulouse en mayo de 1814 en Archives du Ministère des Affaires Étrangères, Mémoires et documents, Espagne, vol. 381.

19. Bulletin des Lois du Royaume de France, París, de l'Imprimerie Royale, 1815, no 388, p. 311: Viado «est admis à établir son domicile en France, et à y jouir de tous les droits civils, tant qu'il continuera d'y résider».

20. Así lo afirma en el citado expediente custodiado en AHN, Universidades, leg. 672, ㄲo 37.

21. Mémoires de l'Académie des Sciences, Inscriptions et Belles-Lettres de Toulouse. Septième série. Tome VIII, Toulouse, 1876, p. 318. Allí publicaría «Mémoire sur l'origine de l'architecture européenne, depuis le $\mathrm{XIII}^{\mathrm{e}}$ siècle jusqu'à la fin du $\mathrm{XV}^{\mathrm{e}}$ 》 (Histoire et mémoires de l'Académie Royale des Sciences, Inscriptions et Belles-Lettres de Toulouse depuis son rétablissement en 1807, t. I, $2^{\mathrm{a}}$ parte, Toulouse, Imp. 
de Jean-Matthieu Douladoure, 1827, p. 77). Agradezco al profesor Jesús Sánchez Miñana estas informaciones.

22. De nuevo según el sobrino de Viado (quien también se hace eco de su nombramiento en la citada academia de Toulouse).

23. Su nombre figura en una «Liste des réfugiés civils espagnols qui résidaient à Paris le 19 septembre 1815» (Vincennes, Réfugiés Espagnols, carton 60. Citado por Solange Bégué, «L'Invasion napoléonienne jugée par l'opinion publique espagnole (1814-1820)», en VV.AA., Actes du $94^{e}$ Congrès National des Sociétés Savantes. Pau, 1969 (Section d'Histoire Moderne et Contemporaine, t. I), París, 1971, p. 314).

24. París, 1816, t. I, p. 53: «partisan prononcé des monarchies constitutionnelles».

25. En AHN, Estado, leg. 8.723, exp. 123-125, se conservan varios oficios, fechados en Burdeos en 15 de noviembre de 1818, en los que propone al gobierno español escoger tierras baldías en Venezuela y ponerlas a la venta en lotes. Viado mantendría este interés por las tierras americanas (donde, no lo olvidemos, su suegro hizo negocios durante varias décadas), como veremos más adelante.

26. El expediente detallado del proceso se encuentra en AGP, Papeles reservados de Fernando VII, tomo XIX, carpeta 14. En su estrategia defensiva, además de intentar desvincularse de la autoría de sus escritos masónicos, intentó despistar a sus acusadores omitiendo datos sobre su estancia en Francia en los últimos años y presentándose como un refugiado más, uno de tantos que tuvo que vagar durante años por diferentes depósitos de refugiados, que cita, cuando en realidad, como hemos visto, su vida en Francia quedó relativamente pronto bien encarrilada, primero en Toulouse y luego en París y Burdeos.

27. AHN, Estado, leg. 5.335, exp. 120.

28. Más de una década en la que no solo se formará como militar, y participará en la guerra de la Convención, como vimos, sino que, uniendo la pluma con la espada, escribirá en 1802 un Proyecto de reforma del ejército español, en el que, con verdadera clarividencia, llegará a predecir la invasión napoleónica de España, para lo que urgía a una profunda reforma del mismo. Muy a mi pesar, no he conseguido localizar este texto, que sin embargo debió existir, pues la Biographie des hommes vivants..., op. cit., p. 53, ofrece una cita textual.

29. «Advertencia», en El Revisor político y literario, t. I, cuaderno 1, 10 de agosto de 1820, p. 2. Viado alude, es obvio, a la competencia, mucho más poderosa, del semanario El Censor, cuyo primer número apareció precisamente en aquellos mismos días.

30. No tenemos noticia alguna de la tirada, pero sí hay constancia de segundas ediciones de algunos números, como se encarga de publicitar su autor. El lector interesado puede acceder a este periódico en la Hemeroteca digital de la Biblioteca Nacional de España.

La distribución es modesta, al menos si la comparamos con un competidor como la Miscelánea de Javier de Burgos, que contaba con 32 puntos de venta por todo el país, además del recurso a la estafeta de Correos. Por ello, en buena medida la suerte del periódico dependía de la fiabilidad del servicio postal, que no debió de funcionar como Viado esperaba, a tenor de las burlas de la Periodicomanía que, al expirar el periódico, comentó con sorna que fue «íntimo amigo de los administradores de Correos de todo el reyno. Correspondíase con ellos cariñosamente, y ellos no correspondieron» (n⿳⺈ 34, p. 20-21).

31. Periodicomanía, $\mathrm{n}^{-}$19, p. 24.

32. El Constitucional, o sea, Crónica científica, literaria y política, 30 de diciembre de 1820, [p. 4].

33. Miscelánea de Comercio, Política y Literatura, 13 de agosto de 1820 , elogios que repite en el número de 24 de diciembre; El Universal, 3 de septiembre de 1820 (pronto se enfriarían las relaciones de Viado con este periódico).

34. Analizo estas características en mi artículo «La moderación como divisa. En torno al ideario político de los afrancesados», en Pedro Rújula y Jordi Canal (eds.), Guerra de ideas. Política y cultura en la España de la guerra de la Independencia, Madrid, Marcial Pons, 2011, p. 135-155. 
35. La cita en El Revisor, t. I, cuaderno 3, 30 de agosto de 1820, p. 70. Manuel Silvela recomendaba por las mismas fechas idéntica actitud en su obra de teatro El Reconciliador, que he analizado más detenidamente en mi artículo «Manuel Silvela (1781-1832): andanzas y compromiso político de un refugiado afrancesado», en Alberto Romero Ferrer y David Loyola López (eds.), Las musas errantes. Cultura, literatura y exilio en España en la primera mitad del siglo XIX, Gijón, Trea, 2017, p. 37-56.

Todavía en uno de los últimos números de su publicación insistía Viado en la necesidad de graduar las medidas: «Los exaltados (...) han querido sujetar los acontecimientos por la fuerza, sin imaginar que todas las operaciones de la sabiduría son lentas y progresivas; que las de la locura son impetuosas y destructoras; que aun las innovaciones más útiles necesitan llevarse por buen término y ser previamente indicadas por la opinión» (t. II, cuaderno 6, 30 de diciembre de 1820, p. 122).

36. «Del ministerio español» (t. I, cuaderno 4, 10 de septiembre de 1820, p. 74. Esta llamada a la acción es por supuesto compatible con la advertencia de no cometer «excesos que por fuerza habían de producir una espantosa anarquía y llevarnos derechamente al despotismo» (t. II, cuaderno 2, 20 de noviembre de 1820, p. 47), expresiones que por las mismas fechas podían leerse en cabeceras como El Censor o la Miscelánea. También Miñano se exaspera con la lentitud del primer gabinete liberal a la hora de afrontar algunas reformas urgentes (Remito al análisis certero de Claude Morange, Sebastián de Miñano. Sátiras y panfletos del trienio constitucional, Madrid, CEPC, 1994, p. 67-69).

37. Tomo I, cuaderno 8, 20 de octubre de 1820, p. 172.

38. Las citas en t. II, cuaderno 6, 30 de diciembre de 1820, p. 131 y t. II, cuaderno 9, 30 de enero de 1821, p. 195, respectivamente.

39. Remito de nuevo al magisterio de Claude Morange en su trabajo «Teoría y práctica de la libertad de prensa durante el trienio constitucional: el caso de El Censor (1820-1822)», en Siete calas en la crisis del Antiguo Régimen español, Alicante, Instituto de Cultura Juan Gil-Albert, 1990, p. 87-105.

40. Tomo I, cuaderno 7, 10 de octubre de 1820, p. 161.

41. «De la opinión pública», t. II, cuaderno 1, 10 de noviembre de 1820, p. 7. El Constitucional del 13 de noviembre calificaría este número como «uno de los más interesantes que ha publicado hasta ahora El Revisor».

42. Carta $1^{\text {a }}$ de $E l$ Cobadondo, en t. I, cuaderno 1, 10 de agosto de 1820, p. 20-21, en respuesta al artículo «Reuniones patrióticas» publicado por El Censor, nº 1, 5 de agosto de 1820, p. 65 y ss.

43. «Proyecto de ley sobre sociedades patrióticas», t. I, cuaderno 6, 30 de septiembre de 1820, p. 141-142.

44. Baste un ejemplo: «¿Cómo puede radicarse en los corazones de los españoles el principio de la igualdad, cuando se tropieza por todas partes con uniformes privilegiados, con escarapelas, galones, cruces, cintas y garambainas, señorías, reverendísimas, ilustrísimas y excelencias?» (t. II, cuaderno 9, 30 de enero de 1821, p. 210).

45. Para lo que aprovechó, casi literalmente (tan solo eliminando algunos párrafos o sustituyendo palabras clave) sus trabajos de 1812 y 1813. Así, el artículo «De la influencia de la buena filosofía en los progresos de la ilustración y de las ideas liberales» (t. II, cuaderno 4, 10 de diciembre de 1820 , p. 73-80), un canto a la tolerancia como arma frente al fanatismo y la ignorancia, es casi un calco de su citado discurso masónico de 1812. Por su parte, en el titulado «Del poder de la tiranía en el atraso de las ciencias y de la literatura en España» (t. II, cuaderno 2, 20 de noviembre de 1820 , p. 25-40), de nuevo una apelación a la fraternidad, aprovecha párrafos enteros de los artículos que publicara en la Gaceta de Madrid en febrero y marzo de 1813. Para un análisis en profundidad de ambos textos remito de nuevo al citado trabajo de Juan Pablo Domínguez.

46. Tomo II, cuaderno 9, 30 de enero de 1821, p. 214. 
47. «Si algún día ocurriese diferencia de opiniones o de intereses entre los patriotas de 1812 y los de 1820, cuando el peligro común los llame (...) todos correrán presurosos a olvidar resentimientos para atender a la defensa de las instituciones liberales», escribe confiado en una llamada a la paciencia de los más jóvenes (t. II, cuaderno 2, 20 de noviembre de 1820, p. 47), a la vez que pide a los veteranos de 1812 «asociar a sus trabajos y hacer partícipes de los empleos (...) a la juventud que nos redimió del duro cautiverio» (t. II, cuaderno 1, 10 de noviembre de 1820, p. 5).

48. Dedicará varios artículos a la Educación, «la palanca poderosa de cuantas reformas hay que hacer» (t. II, cuaderno 3, 30 de noviembre de 1820, p. 56); propondrá una nueva división geográfica de España en la que «el castellano, el aragonés, el catalán y el vascongado olviden sus divisiones con los nombres que las han perpetuado» (en una llamada al centralismo en la que resuenan ecos del proyecto que Amorós presentara al rey José unos años antes) (t. II, cuaderno 3, p. 51-54); la reforma del Ejército (t. II, cuaderno 7, 10 enero 1821, p. 145-155) un tema que conoce muy bien desde que en 1802 publicara su citado trabajo, y por supuesto la Economía, ciencia en la que se declara fiel partidario de los postulados de los economistas ingleses y a la que dedicará artículos en los que aborda desde la denuncia de la falta de cultura financiera, a la necesidad de promover el comercio interior, el estudio de los mayorazgos, los diezmos o la deuda pública, asunto éste en el que mantendrá una sonada polémica con El Universal.

49. «Aviso», t. II, cuaderno 7, 10 enero 1821, p. 167.

50. La Periodicomanía, no 31, p. 20-21. Cuando un mes más tarde finalmente desapareció, el mismo periódico le despidió definitivamente, con igual ironía, desde el nํ 34, p. 20-21.

51. «Aviso», t. II, cuaderno 9, 30 enero 1821, p. 214-215, cita p. 215.

52. Biographie des hommes vivants..., op. cit. Por desgracia, no he encontrado rastro de esta traducción, que forzosamente tendría mucho interés, según los indicios que vamos viendo. En 1822, 1827 y 1840 aparecieron sendas traducciones, pero ninguna de ellas de su mano. Viado prestó siempre mucha atención a América, y en El Revisor serán frecuentes los artículos de esta temática. En ellos mantiene todavía esperanzas ante una posible reconciliación, y muestra un recelo ante las intenciones de los EE.UU. que despertaría de nuevo las chanzas desde La Periodicomanía. Sobre el interés de los antiguos josefinos hacia este tema me permito remitir a mi artículo "América en el pensamiento de los afrancesados», en Francisco Javier Caspístegui e Ignacio Peiró (eds.), Jesús Longares Alonso: el maestro que sabía escuchar, Pamplona, Eunsa, 2016, p. 159-182.

53. Encuentro esta noticia en el Diario Constitucional, político y mercantil de Palma, oㅡ 61, 30 de noviembre de 1822, p. 1.

54. Ya en mayo de 1824 firmaba una carta comercial, desde Madrid, dirigida a un comerciante de La Habana, cuyo texto fue transcrito en F. J. Yanes, Origen y objeto de las reclamaciones del Gobierno francés de la Martinica contra la marina de Colombia..., Caracas, 1825, p. 10.

55. Guía mercantil de España. Año de 1829, Madrid, Imp. de I. Sancha, s.a., p. 392.

56. Localizo esta referencia en el Diario Balear, $n^{\circ}$ 21, 21 de enero de 1834, p. 3. Ese mismo año figura ya como consiliario en el Banco Español de San Fernando (Calendario manual y guía de forasteros en Madrid para el año de 1834, Madrid, Imp. Real, 1834, p. 200).

57. De nuevo en el Diario Balear, $\mathrm{n}^{\circ}$ 86, 25 de junio de 1835, p. 1. Se cita a Viado como «ministro honorario del Tribunal mayor de Cuentas». Todavía en octubre de 1838 se le incluye en una comisión de expertos «de conocimientos mercantiles, de probado celo, y de opinión bien recibida en el Comercio» para revisar diferentes artículos del Código de Comercio (Boletín oficial de Segovia, no 133, 13 de noviembre de 1838, p. 537-538).

58. Más allá de sus actividades en «el comercio de la capital», Viado tuvo cierta participación en una empresa que, en 1829, se constituyó en Granada para explotar unas minas de cobre y plomo en Linares, actividad que tuvo éxito inicialmente pero que fue decayendo hasta el abandono de la explotación en 1841. Véase F. Gutiérrez Guzmán, Las minas de Linares. Apuntes históricos, Linares, 
1999, p. 185-186 y 521-522. Viado ya dio muestras de su interés por la minería (que vive un claro despertar desde la aprobación de la ley de minas en 1825) a través de varios artículos en El Revisor, donde reclamaba ya entonces la explotación de las minas españolas (t. I, p. 92-94; t. II, p. 108).

59. Madrid, Oficina de Don Tomás Jordán, 1837, 16 p. Viado aboga por mantener este impuesto, siempre que sea el Estado, y no la Iglesia, quien lo recaude, y que se destine una parte de su importe al mantenimiento del clero y el resto para aliviar las cargas de los contribuyentes (un resumen en Gaceta de Madrid, 24 de marzo de 1837, p. 3). Precisamente en El Revisor dedicó atención al diezmo (t. I, p. 12-16 y 80-88) reclamando ya entonces una urgente reforma de esta tasa, que considera una «cuestión clave» (t. I, p. 80).

60. Revista de Madrid, t. II, diciembre 1838, p. 247-281.

61. Viado comenzó aquel año como teniente de alcalde al frente de uno de los doce distritos en los que estaba dividida la capital, pero cuando, en abril de aquel año, dimitió el alcalde Manuel de Larrain, ocupó provisionalmente el cargo. A finales de ese mes encontramos el primero de los bandos que firma como flamante alcalde constitucional (Diario de Madrid, 27 de abril de 1844), en el que debió de mantenerse durante poco más de un mes. Unos años antes, en 1839, su nombre llegó a ser barajado en algunos medios como posible ministro en el gabinete presidido por Pérez de Castro. De ello se hizo eco, por ejemplo, La Presse, de París, en su número de 21 de abril de 1839.

62. Esta correspondencia con María Cristina, así como sus informes sobre el transcurso de estas elecciones (que tuvieron lugar entre el 20 y el 25 de mayo de aquel año) en AHN, Diversos-TítulosFamilias, 3390, leg. 94, exp. 28.

63. La carta está fechada en Bayona el 5 de agosto de aquel año, y en ella Miñano expresa sus deseos sobre «el más feliz resultado de su viaje con nuestro querido enfermo», le ofrece «mis respetos a su señora madre» y le anuncia que acaba de vender su casa en Bayona, «donde Vm. tuvo la bondad de visitarme». Puede verse en J. Simón Díaz, Colección de Índices de publicaciones periódicas, IV: Semanario Pintoresco Español (Madrid, 1836-1857), Madrid, CSIC, s.a., p. LIV-LV.

En la correspondencia con la antigua reina regente Viado ya le anunciaba su próximo viaje a este balneario francés, por lo que es más que presumible que la visita a «Buruchuri», la casa donde vivía Miñano, fuera de toda la familia, incluida nuestro Manuel. El viejo Miñano moriría tan solo unos meses después, en febrero de 1845.

\section{RESÚMENES}

El presente artículo pretende mostrar la trayectoria de Manuel Alonso de Viado (1774 -d. 1844), un personaje polifacético (militar, emprendedor, escritor, ferviente masón, comerciante, periodista y político), hoy totalmente olvidado, y su intención de influir en la apasionante coyuntura del Trienio liberal a través de su periódico El Revisor político y literario (1820-1821).

Cet article rend compte de la trajectoire de Manuel Alonso de Viado (1774-p. 1844), personnage polyvalent (militaire, entrepreneur, écrivain, fervent franc-maçon, commerçant, journaliste et politicien), aujourd'hui complètement oublié, et son souhait d'influer à travers son journal $E l$ Revisor político y literario (1820-1821) sur la conjoncture passionnante du Triennat libéral. 
This article aims to show the trajectory of Manuel Alonso de Viado (1774- p. 1844), a versatile figure (military, entrepreneur, writter, fervent mason, trader, journalist and politician) today totally forgotten, and his intention to influence the exciting juncture of the Trienio liberal through his newspaper El Revisor politico y literario (1820-1821).

\section{ÍNDICE}

Mots-clés: Trienio liberal, journalisme, franc-maçonnerie, engagement politique, Manuel Alonso de Viado

Palabras claves: Trienio liberal, periodismo, masonería, compromiso político

Keywords: Trienio liberal, journalism, Freemasonry, political compromise

\section{AUTOR}

\section{JUAN LÓPEZ TABAR}

Urgoiti Editores 